\title{
A Balanced Embedded Elder Care Model: A Case Study on the Family Elderly Care Beds in T Community of Nanjing
}

\author{
WEI Yi
}

School of Public Affairs, Nanjing University of Science \& Technology, Nanjing, Jiangsu 210094, China

*Corresponding author. Email: 953651038@qq.com

\begin{abstract}
Family Elderly Care Beds is an innovative elder care service to cope with the aging population in Nanjing, China. It directly embeds the various modern aging equipment and kinds of service resources into the house, so that the elderly can enjoy professional, personalized and convenient services without leaving their place. Through field investigation, semi-structured interview and other methods, this paper takes the operation mode of Family Elderly Care Beds in T community of Nanjing as an example, aiming to analyse how does this service integrate and embed diverse resources from time dimension, emotional dimension and resource dimension and how to realize the effective balance between supply resources and diversified demands in elder care.
\end{abstract}

Keywords: elder care service, case study, embeddedness theory

\section{迈向一种平衡性的嵌入式养老模式 关于南京市T社区家庭养老床位运营的个案分析}

\author{
韦汽
}

南京理工大学 公共事务学院, 江苏 南京 210094

*联系方式: 953651038@qq.com

\section{摘要}

家庭养老床位是南京市为应对人口老龄化的创新之举。家庭养老床位以嵌入式养老的方式，将适老化 设备及配套服务资源整合，让老人在居家中享受专业化、个性化、便利化的养老服务。本文通过文献 调查、实地调查、半结构式访谈等方法, 以南京市 $\mathrm{T}$ 社区的家庭养老床位运行模式为例展开调查, 从 时空维度、情感维度、资源维度分析养老服务资源通过 “家庭养老床位” 进行 “嵌入” 的过程，最终 实现了养老资源和多元化养老需求的有效平衡。

关键词：嵌入式养老，家庭养老床位，养老服务

\section{1. 研究背景}

随着我国人口老龄化进程的快速发展和城乡居民 生活水平的提高, 养老服务的需求呈现出就地化、多 元化、个性化的特征, 但专业的养老服务资源却无法 满足多重的需求，呈现 “供需失衡” 的状态 [1]。而我 国人口老龄化发展态势迅猛, 预计到 2050 年, 我国老 年人口将会增长到 4.83 亿, 80 岁及以上高龄老年人口 将达到 1 亿, 高龄比（高龄老年人口占老年人口总量的 比重）达 $22.3 \%$, 占世界高龄老年人口总量的 $1 / 4[2]$ 。 高龄化趋势相伴而来的 “病苦老龄化” 更值得关注,
即长寿而不健康的老人在增多, 失能、半失能老年人 的规模也在不断扩张 [3]。为积极应对人口老龄化的挑 战, 党的十九届四中全会强调 “加快建设居家社区机 构相协调、医养、康养相结合的养老服务体系”。

“嵌入式” 养老模式的政策导向致力于将社区居家养 老和机构养老的优势加以整合。但是, 如何 “嵌入” 以实现养老资源与需求的有效对接仍是亟待解决的难 题。

在各地的探索中，南京市引起了全国的注意。南 京是全国较早进入人口老龄化城市，至2018年末，南 京60岁及以上户籍老年人口占户籍总人口 $21.07 \%$ ，已 进入深度老龄化社会 [4]。在2017年出台了实施办法后, 
南京市政府于 2018 年在鼓楼区开展家庭养老床位建设， 针对居家的失智、失能、半失能老人, 以社区为依托, 将适老化设备及配套服务 “嵌入” 老人家中, 能够充 分有效地盘活周边的养老服务资源, 让老人能够在不 脱离现有的熟悉的生活环境和社会关系网络的前提下 享受专业化、个性化及便利化的养老服务。这项家庭 养老与机构养老相结合的服务模式属全国首创, 目前 已经初步成型, 在北京、广州、上海、武汉等地也相 继实施。

本文以 “嵌入式” 为视角, 探讨 “家庭养老床位” 这一嵌入养老模式的发展现状及其特点。在对相关政 策和文献进行梳理的基础上，2019年7月至8月，作者 在南京市 T社区走访了15户接受家庭养老床位的家庭, 访谈了该区民政局相关负责人以及养老服务Y机构的家 庭养老床位负责人, 深入了解了关于嵌入式养老新模 式一一家庭养老床位的运行情况。

\section{2. 文献回顾}

卡尔·波兰尼在《大转型》中最先提出“嵌入”概念, 即一个系统有机结合进另一个系统之中或者事物内生 于其他事物之中的客观现象 [5]。而后, 格兰诺维特丰 富并发展了嵌入理论, 对原本宏观抽象的“嵌入”理论 进行普适化、微观化和可操作化, 将嵌入的焦点转到 人的行动嵌入在社会关系网络的研究中 [5]。目前, 嵌 入式的内涵已逐渐泛化, 其应用范围也从经济学领域 不断扩大, 在社会学领域也广泛适用。如Hangedoorn 认为嵌入性可以分为环境嵌入性、组织间嵌入性和双 边嵌入三个层次[6]。Zukin and Dimaggio 将嵌入层次分 为认知嵌入、结构嵌入、文化嵌入和政治嵌入四种 [7]。 何跃等将运用将社会组织嵌入农村社区的过程按照嵌 入前、嵌入中、嵌入后划分进行评估分析 [8]。王思斌 通过将嵌入性分为嵌入的前提、过程、机制和状态, 来研究社工作嵌入发展的格局和变化 [9]。可见关于“嵌 入” 的概念操作化已经相对成熟, 为本文划分分析维度 提供了借鉴。

在养老服务领域, “嵌入”理论也为其提供了一种 新型的实践与分析视角。迄今, 学术界关于“嵌入式养 老”的研究尚处于起步阶段, 对“嵌入式”养老模式的概 念界定仍然存在分歧, 研究多涉及在各地区嵌入养老 模式的案例分析和经验总结。胡宏伟等通过比较了国 内部分实践典例, 对 “嵌入式”养老模式进行了优势分 析, 认为“嵌入式” 养老模式是社区为载体, 以资源嵌 入、功能嵌入和多元的运作方式嵌入为理念, 在社区 内嵌入一个市场化运营的养老方式, 整合周边养老服 务资源, 为老年人就近提供多元化服务的一种模式[10]。 章萍基于社会嵌入理论, 总结上海市社区嵌入式养老 模式经验, 认为该模式依托社区关系网络, 充分利用 各种社会资源, 克服了家庭养老与居家养老社会化不 够难以获得足够社会资源的缺点, 也弥补了机构养老 因过度社会化难以满足老人家庭情感需要的不足 [11]。 赵小兰以各地社区嵌入式养老模式为分析案例, 认为
“嵌入式”不仅克服了居家养老、社区养老和机构养老 的局限性，又在居家和社区之间形成有效的服务传送 和服务闭环, 结合了三者的优势[12]。各研究总结了各 地嵌入式养老发展的基本运行体制及其特点，在定义 上也各有侧重。据此，本文将“嵌入式养老”理解为在 不脱离服务对象原有生活环境的情况下, 整合周边养 老服务资源, 通过多重维度的嵌入为服务对象提供便 利化、多元化、个性化、专业化服务的养老模式。

从养老服务的实践来看，这种“嵌入式”养老综合 了社区居家养老服务和机构养老服务的优势，是一种 致力于弥补单一养老服务模式的资源匮乏来实现“供需 平衡”的新型养老模式。2013年，上海在全国率先实践 “嵌入式”养老模式，此后北京、重庆、石家庄等城市 也先后引入该服务模式。上海市实施的长者照护之家 嵌入式养老服务, 以微型、运营专业化、功能多元化 为特点, 小规模的养老机构嵌入社区当中, 将其拥有 的养老资源和专业服务直接辐射到家庭中。此外, 王 晶等认为目前上海市嵌入养老模式在为老年人提供社 会化平台、社会支持网络以及整合社区资源三个方面 也具有优势 [13]。北京由街道办投资建设“嵌入式”养老 服务驿站, 社区负责运营, 其他福利机构可以嵌入合 作，形成“政府一街道办一社区”三级管理体制 [14]。同 时, 周悦指出层级制的服务驿站存在从“站点一组织一 行业一产业”的发展桎梏, 包括盈利与风险管控、人员 与设施管制、服务与功能管理、扶持与绩效评价等问 题[14]。重庆模式是政府投入，强调社区和居民互动， 租赁居民房分区、幢建立养老照料中心[10]。石家庄模 式主要参照的是美国 CCRC (Continuing Care Retirement Community），实行高端养老，所有有意愿 入住的老人均可缴费入住，但费用相对较高[10]。值得 注意的是，上海地区的“嵌入式”养老以政府购买型为 主, 政府的主导一定程度化解了资源冲突, 但也导致 了社会资本参与度低、规模效应不明显等问题。而北 京重庆地区则是由政府投入资金，社区根据老年人的 情况来进行资金资源调度和人员结构的调整，灵活性 较强。

当前“嵌入式”养老的研究大多涉及对地区实施经 验的特色归纳和经验总结, 对嵌入式理论的操作化缺 乏不同维度的实证分析。那么，如何充分发挥“嵌入式” 养老的多维优势以达到养老需求和服务资源之间的平 衡, 仍然是需要深入探索的一个问题。据此, 本文将 以家庭养老床位这一嵌入养老模式为例, 从不同的维 度探讨如何实现养老服务与资源的合理嵌入。

\section{3. “嵌入式” 家庭养老床位的运作模式}

所谓“家庭养老床位”, 是为了满足居家失能、半 失能、失智和经评估认定特定照顾等级的老人, 进行 家庭适老化设备改造, 把专业养老机构的设备搬到老 人家中，同时对老人进行家庭照护的一种养老模式。

为积极应对人口老龄化, 全国各地都在探索“嵌入 式”养老的新模式。2019年5月9日, 全国大城市养老服 
务工作会议暨全国养老服务推进会议在南京召开，南 京市鼓楼区作为“嵌入式”养老重点示范区, 自推行以 来便引发各界的密切关注, 而“家庭养老床位”的实施 更是为嵌入养老模式开辟了新视野。至2017年末, 鼓 楼区60周岁及以上老年人口占总人口的 $24.05 \%$, 位列 全市各区首位, 且百岁以上老人有 66 人, 已全面进入 高龄化社会[15]。2018年, 南京市家庭养老床位的建设 在鼓楼区率先展开, 在管理细则[16]出台后, 政府颁布 2500余张家庭养老床位, 现已经全部由专业养老机构 认领并且安装入户。

据此, 本文选择以南京市鼓楼区 $\mathrm{T}$ 社区作为调查地 点, 该社区为第一批实施家庭养老床位的社区之一, 至2018年下旬开始建设家庭养老床位, 目前由4A级养 老服务机构 $\mathrm{Y}$ 机构承包服务, 共认购151张床位, 现已 全数投入使用。在 $\mathrm{T}$ 社区共接受该服务的 151 名对象中, 三分之一为失能、半失能老人, 三分之二为自理能力 较低或处于“空巢”状态的老人。所有服务对象都接受 了基础的适老化设备服务, 32名老人还订购其它配套 服务, 主要内容涉及助餐、卫生、护理三个方面。在 $\mathrm{T}$ 社区, 作者访谈了Y机构家庭养老床位负责人, 将 151 位服务对象分为失能、半失能、健全老人三组, 通过 分层随机抽样选择各选择了 5 位失能、半失能和健全的 老人进行走访, 在得到访谈对象许可的前提下进行录 音记录, 并转化为逐字稿进行分析。结合政策资料, 下文将从宏观和微观层面进行阐述家庭养老床位, 重 点分析在微观嵌入层面各个主体的作用及其运行机制。

在宏观层面上, 家庭养老床位的基本运行流程如 下: (1)政府发布养老床位数量——(2)养老机构认购床 位——(3)入户安装、实施服务——(4)评估与补贴。政 府和民政局发挥统筹全局的作用, 通过两种显性政策 工具实现了家庭养老床位的“嵌入”。第一是强制类的 实施条例、细则并提供财政补贴; 第二是同时引入市 场竞争机制, 机构采取自愿认领的形式来确定负责的 床位数量, 在后续政府引入第三方评估运行成效, 作 为是否补贴的标准, 宏观层面的能动性较强。

在微观层面上, 本文将根据“嵌入”的概念, 对嵌 入家庭养老床位服务的主体、客体及内容进行梳理和 分析。

第一，嵌入主体是提供家庭养老床位服务的养老 服务机构及其员工。关于主体的资质也有严格的限制, 服务机构必须为正式注册地具有养老服务从业资质的 A 级以上养老机构或 AAA 级以上社区居家养老服务中 心; 服务人员必须持有国家或部门认可的相关执照或 培训证书[16]。对嵌入主体资质的严格把控是保证嵌入 过程和服务质量的关键, 嵌入主体的主动嵌入是在微 观层面家庭养老床位运作的起点。

第二, 嵌入的客体, 即服务对象, 主要为失智、 失能、半失能老年人。但根据条例规定, 凡是具有鼓 楼户籍的有养老机构床位专业服务需求但因各种原因 无法或不愿入住养老机构内部或家庭有一定的照料条 件暂时无需入住养老机构内部的老年人都是家庭养老 床位的服务对象 [16]。可见家庭养老床位是针对特殊的 老人群体提供的服务, 而这样也使得家庭养老床位服
务具有一定的依附性。一方面，服务对象的特殊性使 得家庭养老床位的服务范围是有限的, 而针对失能、 失智老人的服务内容也提高对服务机构的要求; 另一 方面，在运营初期缺乏经验和完备的政策指导，大多 服务机构将家庭养老床位服务依附于居家养老服务框 架下, 部分服务的内容和收费标准沿用居家养老服务 的项目和收费标准, 以方便该服务的推广。

第三、嵌入的内容。“嵌入式”家庭养老床位的服 务设施分为基本设施、自选设施和专业设施三部分, 在“硬件”方面主要以适老化基本设施改造为主，以大 部分老人家庭已有基础设施（例如床、无线网络、电 脑等）为依托, 配合养老床位设施开展服务。“软件” 服务则是包括自选和专业设施中的个性化服务。

表 1 : 家庭养老床位服务内容

\begin{tabular}{|c|c|c|}
\hline 基本设施（14项） & 自选设施 & 专业设施 \\
\hline $\begin{array}{l}\text { 摄像头和远红外感应器、 } \\
\text { 床头一键呼叫器、语音视 } \\
\text { 频和通话设备、家庭网、 } \\
\text { 烟感探测器、门磁感应 } \\
\text { 薟、焒、漏水报 } \\
\text { 㗊、体感应小掖灯、手、U型扶、手、L型 } \\
\text { 扶手、防滑垫、体征检测 } \\
\text { 仪。 }\end{array}$ & $\begin{array}{l}\text { 服务对象 } \\
\text { 向服务位 } \\
\text { 租赁或购 } \\
\text { 买。 } \\
\text { (如：助 } \\
\text { 餐、足 } \\
\text { 生、医护 } \\
\text { 等) }\end{array}$ & $\begin{array}{l}\text { 由各服务 } \\
\text { 机构根据 } \\
\text { 服务需求 } \\
\text { 选 配 。 } \\
\text { (如: 护 } \\
\text { 理员/护工 } \\
\text { 人员安排 } \\
\text { 等) }\end{array}$ \\
\hline
\end{tabular}

“嵌入式” 家庭养老床位充分调动了多方面的服 务资源, 服务内容涉及生活照料服务、电子信息化服 务、康复护理服务、医疗护理服务、精神慰藉、文化 娱乐等服务，多元化的嵌入内容减小了嵌入主体在应 对服务对象各种个性化需求时的压力，是 “嵌入” 环 节中的必须要素。与其它单一的养老服务相区别, 家 庭养老床位对服务的整合是现代养老和传统养老的融 合。

作为家庭养老床位运行的先锋, 南京市鼓楼区已 初步探索出在政府主导下以社会参与、资源整合、多 维嵌入为特点的 “嵌入式” 家庭养老床位运行机制

（如图1）。那么家庭养老床位模式是如何实现 “平衡” 地 “嵌入” 呢, 下文将对多维度的嵌入进行继续探讨。

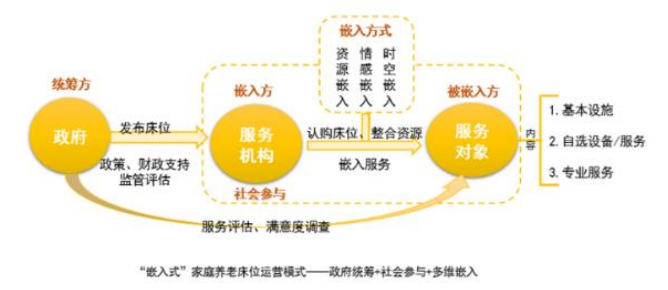

图1：“嵌入式”家庭养老床位运行机制

\section{4. 时空、情感与资源：家庭养老床位的嵌入 维度}

本文采用半结构式访谈的方式收集资料, 并根据 访谈的对象将资料分为两类。一类是与 $\mathrm{Y}$ 家庭养老床位 负责人和服务人员的访谈资料, 另一类是与 15 户家庭 
（包括家属和老人）的访谈资料。整理两类访谈对象 的回答, 主要围绕家庭养老床位服务的便利、专业、 多元等照顾特点, 进而基于嵌入的视角梳理出家庭养 老床位是围绕以下三个维度实现服务的嵌入, 以实现 对特殊老人群体的多方位照顾。

\section{1. 时空嵌入}

第一、缩短时空距离。家际空间距离直接影响家 庭代际成员之间的时空交会轨迹, 家际距离近甚至世 代同居下子代与父代共处, 使子代提供的老年人照顾 与慰藉具有时空可行性 [17], 有助于提高养老幸福感。 相比于单一的机构养老或是家庭养老, 嵌入式的家庭 养老床位服务缩短了时空照顾距离。

案例一: 百岁老人孙奶奶, 三代同堂。接受家庭 养老床位服务一年，订购日常护理、生活照料等服务。

作者:孙奶奶，张阿姨（护理员）每天都来呀?

孙奶奶: 是的呀, 儿子媳妇上班了她就来, 做饭 也好吃的, 多亏了她。

张阿姨: 哪里哪里, 这是我的工作。

作者:张阿姨，您每周上门服务多久呀?

张阿姨: 一般是周一到周五，他们（指儿子儿媳） 上班时候我就来。做饭和打扫卫生, 老人右手臂不好 (有残疾), 有时候要做一下康复锻炼。我原来就是 在Y机构养老院干护工的, 后来那边联系我做上门服务, 离得近我就来这边千。

作者: 这样啊, 那孙奶奶有了您专业的陪护，家人 一定也很放心。那关于其它的家庭养老床位设备都投 入使用了吗?

孙奶奶: 都有的, 家里都装起来了的。烟雾报警 器很有用的, 有一次家里烧水没有及时关, 它都响了 的，关的时候水差点烧千了。

案例中的孙奶奶与儿子一家同住, 在世代同居的 情况下, 子代家庭成员的时间张弛度较大, 家庭照顾 的时间密集度也增多, 老人认为有子女的陪伴才是理 想的老年生活。但成年子女在陪伴老年父母时又需要 兼顾自身家庭的运转, 就产生了两个小家庭照顾之间 的紧张感, 那么在子女上班时就需要保障对父母的照 顾, 家庭养老床位服务的上门形式就缓解了这样的压 力, 并在保障了家庭养老功能的同时引入了专业机构 养老服务。在居家空间中嵌入了专业、智能的养老设 备, 实现了把养老院 “搬” 回家的环境改造, 并弥补了 在机构养老而无法与亲人团聚的时间。中国大多数养 老机构和养老院都设置在偏远的郊区, 环境陌生且成 本高。虽然社区居家养老服务建设取得了很大进展, 但是, 大多数城市的社区居家养老仍然停留在以提供 最为基本的公共服务的阶段 [18], 所能够服务的老年 人也较为有限, 尤其是对于失智失能的老人, 社区居 家养老所能够提供的服务无法满足其需要。家庭养老 床位服务站设置在社区居家养老服务中心, 缩短了上 门服务的物理距离, 平衡了获取服务和享受服务的时
间，即减少了老人外出接受服务的通勤时间，增多了 亲情陪伴、居家养老的时间。

第二，院舍照顾和家庭照顾的时空交汇。社区照 顾理论下院舍照顾和家庭照顾结合得以实现的关键在 于运用社区的各种正式与非正式资源, 达到使需要照顾 的老人能够继续留在社区或他们原来的生活环境下维 持独立生活, 同时又能获得必要照顾的理想社区照顾 [19]。家庭养老床位服务符合社区照顾理念，将服务 对象缩小到行动不便的高龄、失能半失能老人, 达到 了时空上两种照顾方式的交汇。通过与服务人员的访 谈了解到, 家庭养老床位服务有政策导向和财政补贴, 也有养老机构的专业服务和社区站点的支持，在融合 两类照顾方式上具有优势。

作者：王老师，家庭养老床位采取上门服务的方 式, 考虑到了失能老人们出行不便的因素, 那会不会 对服务人员的要求更高了?

王老师（Y机构家庭养老床位负责人）：会的，因 为我们本身也有养老院服务, 但是有些老人不愿意去 住, 离家太远了。那正好有这个政策, 我们机构就直 接从养老院调专业的护理员来上门服务, 比如孙大爷 就是从我们养老院直接回家住的。

作者: 孙大爷是属于哪一类的服务对象呢?

王老师: 他腿做过手术, 80 多岁了, 我们每天都会 上门护理，老人家就在家等就好了。一般是中午、下 午去, 晚上他儿子下班回来也会照顾他, 有那个监控, 有什么事我们和家人可以直接在APP上观察到。

作者：真好，老人白天有你们照顾，子女下班了 晚上也有人陪伴。那从站点到服务对象的家远吗?

王老师：不远的，站点在整个社区的中心，最远 的小区骑电动车十分钟也到了。老人家如果走过来那 就不方便, 也不安全。

各个社区都设有专门的服务站点, 位于服务区域 的中心位置，上门服务的平均距离和花费时间因此减 少, 使专业的院舍照顾进入家庭照顾, 平衡了老人生 活居家形态和地缘性养老服务的需求，在挖掘潜在服 务需求、应对突发事件、防范生活安全方面格外体现 了嵌入式养老服务响应的时效性。在我国, 现存的养 老床位远不能满足庞大的养老需求, 且由于大部分床 位位于偏远的养老机构，在 “养儿防老” 等守旧观念 下，居家养老需求更加剧了主城区养老床位的供需失 衡 [20]。那么在老人的住所安装智能化养老设备, 将 专业机构的设施和服务 “嵌入” 家庭住所中, 缓解了 养老床位供求不足的矛盾, 并在家庭空间中享受院舍 照顾服务。

\section{2. 情感嵌入}

第一，单向传递到双向交互的情感关系嵌入。在 关系性嵌入中, 行动者之间的互动可以形成强连带、 弱连带和无连带三种关系。这三种连带的强弱可以通 过 “认识时间的长短”、“互动的频率”、“亲密 性” (相互倾诉的内容) 和 “互惠性服务的内容” 来测 
量 [21]。关系的强度与对关系的投入呈正相关, 而子女 与父母之间的关系强度是自然产生，随陪伴的时间而 增长的, 那么家庭养老床位则促进了双方的陪伴互动, 重点体现在实现了亲情联络和照护压力的平衡。在走 访的家庭中, 赵先生为母亲订购了家庭养老床位的康 复服务, 他的父亲去世后, 母亲独居了一段时间, 某 天血压升高导致了脑出血, 出院后情况稳定但有些轻 微的偏痽。

案例二: 赵奶奶, 七十多岁, 家里经济状况较好, 出院后儿子想送母亲到疗养院接受康复治疗, 但母亲 不愿意离开家。

作者: 赵先生, 听说您母亲出院后坚持在家养老, 而她行动不便又需要定期的康复锻炼, 为什么不去康 复中心或者好的疗养院呢?

赵先生：老人家不想去没人认识的地方, 我父亲 去世后她一个人, 朋友也都在附近, 虽然她现在行动 不方便, 但是在家里我们下班回家可以陪她聊聊天。 以前疏忽了我妈妈, 觉得让她吃好穿好, 住最好的养 老院就好, 其实她更希望有人陪着。

作者: 是啊, 大多数老人都还是希望有孩子说说 话, 聊聊天。那赵奶奶怎么进行康复运动呢?

赵先生: 我们请了专业的护工, 她这个高血压不 放心, 我们上班没空, 还有就是不够专业怕伤到老人 家, 康复什么家里都买了器材可以铅炼。现在身体慢 慢变好了。

作者: 那真的是太好了, 护工是在安装了家庭养 老床位后向Y机构请的吗?

赵先生: 是的, 是他们养老院的护工, 人也很好。 他们可以上门服务, 我们也不用去医院跑, 老人在家

里舒服, 有监控、警报器, 上班时候我们也放心一些。 而且社区 (指Y机构) 那边也经常会上门看看老人。

赵先生在母亲的生病后更加重视对老人的照顾, 与母亲交谈的时间也增多了, 现在赵奶奶在护工的陪 伴下每天进行一个小时的康复锻炼, 已经能够拄着拐 杖行走, 在周末赵先生也会带着母亲在小区散步, 时 间长了母子之间关系变得更加紧密, 缩小了双方原来 的隔阂, 亲情的陪伴更是互惠性的内容, 随之互动加 强, 形成了一种代际关系之间的强连带关系, 是一种 情感交互的共赢, 而这一种共赢是建立在减轻子代照 顾压力的基础上的。因此, 需要注意到家庭养老床位 的特点, 即为失能、失智的老人提供特殊服务, 是与 传统居家养老的基本服务有所区别的。在走访的15户 老人中, 除去两位独居老人外, 子女上班时7位非全失 能的老人是独自在家, 而基于家庭养老床位的适老化、 智能化设备, 养老机构和子女可以在手机APP上看到老 人的动态, 同时简易的紧急呼叫装置也可以及时通知 到社区的站点, 减轻了子女的照护负担和担心老人独 自在家或是机构养老的心理压力, 有了政府的补贴, 与住养老院相比更是减轻了经济压力, 更重要的是, 老人不用离开子女, 亲情交往日益紧密, 随之形成一 种强连带的嵌入关系, 关系的强度与对关系的投入呈 正相关, 相处时间越长, 互动频率越高, 亲密度随之增强,
互惠性亦随之扩大 [21]，对于子女和老人双方都是一 种共赢的情感嵌入。

第二，显性生理照护和隐形心理照护的兼顾。生 理健康的照护是养老服务的基础, 而隐形照护体现的 是对老人 “独立养老” 需求的照护。“独立养老” 指 老年人在思想上、精神上树立起不依赖子女的观念, 在行动上养成、形成一种相信自己、依靠自己来完成 老年生活中的各项任务的习惯 [22]。

案例三: 独居老人李爷爷, 是一名退休老兵, 身 体还算健康，声称 “不想麻烦子女”，于是坚持自己 在家, 女儿为其订购了家庭养老床位服务。

作者：李爷爷您都快90岁了, 自己住家里人还放 心的呀?

李爷爷：我身体好的，自己可以自己照顾自己。 我女儿住的近, 隔壁楼, 经常来看我的。他们（指Y机 构服务员工）也来的，每天送饭吃。

作者：您还是很硬朗的呀，除了送饭，Y机构还帮 您做什么的叻?

李爷爷: 这个家里装的摄像头, 报警器都是他们装 的，有事我就打电话找他们的。没事我自己好好的， 到处装扶手安全的很。

王老师：您自己小心点的啊，有事打电话给我们 马上就来的。

李爷爷: 谢谢。我很好, 现在的日子和以前比起 来幸福几百倍。我女儿啊你们啊（指Y机构员工）来还 帮我打扫卫生的，其实我自己慢慢扫地也扫得干净。

案例中的李爷爷具有典型的 “独立养老” 意识, 经历过艰苦的军旅生活, 他十分乐观和独立, 对现在 的生活很满意, 不与子女同住是因为他觉得自己完全 能照顾好生活起居, 不愿意依赖子女。这与中国传统 家庭的代际关系有所矛盾, 一直以来中国的家庭关系 是一种 “甲代抚育乙代, 乙代赡养甲代, 乙代抚育丙 代，丙代又赡养乙代” 的 “反馈模式” [23]，这种模 式下子女的照护赡养是一种责任和义务, 老年人期朌 的是 “不离家不离亲” 的养老生活。但随着生活条件 的改善、家庭小型化和养老观念的变化, 老人们也在 生活照顾、精神慰藉方面的自主、自立和独立的意识 增强。家庭养老床位遵循了 “以人为本” 的养老文化 构建基础, 就如各项适老化设备, 在为了保障老人生 活安全的同时, 更是对老人生存尊严的尊重, 而这是 传统养老方式中往往容易忽略的隐形因素, 结合生理 照护和心理慰藉的养老, 才能真正满足老人的养老需 求。

\section{3. 资源嵌入}

第一，养老资源依赖的平衡。在国内，城乡居民 对资源依赖性较强, 影响老人、家庭对养老方式的选 择最主要的因素就是资源 [24]。根据资源依赖理论, 在居民家庭养老方式与政府及社会组织之间的关系中, 无论是政府或社会组织提供资源或服务, 居民家庭在 
促进医养相结合的养老服务体系的 “中国经验”之体

选择养老方式时都会为满足自身发展需要而产生依赖

性，其中对政府资源的依赖性是最强的 [24]。

家庭养老床位服务的运行以政府为主导者, 以服 务机构为实施者, 实现了两种资源依赖主体在外内源 的整合嵌入。外源性嵌入可以理解为拓展了政府的养 老资源, 体现在家庭养老床位宏观的运行机制中, 政 府将家庭养老床位服务以协议、合同的形式承包给有 资质的养老机构或组织, 即将失能半失能老人的服务 需求外包给专业的养老服务人员, 这样保证了家庭养 老床位政策的实际运行, 满足居民对其养老资源的依 赖。内源性的嵌入是进一步输入养老资源，服务对象 的特殊性也决定了内源嵌入的必要, 首先在社区站点 嵌入专业养老组织, 以上门的形式提供服务, 其次以 适老化设备改造将养老院的专业设施 “搬” 到老人家 中, 这也出于服务对象特殊性的周全考虑。二者的合 作降低了单一内源服务的成本, 政府对服务机构和服 务对象的财政支持也缓解了双方的经济压力, 是平衡 居民对政府养老资源的依赖和居家养老的意愿之间的 共赢。

第二、促进社会化的资源整合。在社会嵌入理论 中, 作为嵌入一定社会结构之中的个人, 所进行的行 为选择必然会受到其嵌入的社会关系网络的影响 [21]。 我国社区、居家养老的个性化、专业化养老服务能力 有待提高; 机构养老面临着老年人情感慰藉的缺失, 存在过度社会化问题。养老方式的选择也受到老年人 社会关系网络的影响, 在中国熟人社会和传统家本位 思想的背景下, 多数老年人在选择老年生活时不愿意 脱离现有社会环境和人际网络。在养老服务领域, 嵌 入式养老为化解社会化不足和过度社会化的矛盾提供 了解决办法, 可以将家庭养老床位模式理解为一个整 合资源的平台, 将市场主体适度嵌入到政府和居民养 老的互动之中, 将家庭养老、社区养老、机构养老等 资源都整合到这个平台上, 针对服务对象的特殊性将 服务资源 “嵌入” 到家中，不离开居住环境既克服了 社会化不足的弊端, 又解决了机构养老过度社会化带 来的问题。调查中的十五位老人在社区都有各自的亲 戚和朋友, 其中非失能的五位老人曾参加过社区举办 的活动, 他们对目前的生活状态表示满足, 这样一种 贴近老人生活习惯的具体照顾和 “嵌入式” 养老形态 的建立, 规避了居家养老资源渠道单一和机构养老远 离原有社会关系网络的缺点, 在熟悉的社会环境与人 际关系环绕的社会结构中增强老年生活的安全感和幸 福感, 实现了由单一到综合的养老资源整合, 成为为 失能、半失能老年人提供养老服务的亮点, 有利于老 年人个体与社会结构在融合互动中达到平衡。

\section{5. 结论与进一步讨论}

在养老问题已成为全社会的重点关注对象之际, “嵌入式” 家庭养老床位的实施, 是满足当前养老就 地化、需求多元化、服务个性化需求的创新之举, 也 是积极构建以居家为基础、社区为依托、机构为补充,
现。

家庭养老床位模式是一种迈向平衡的多维度嵌入 式养老, 在时空维度上, 体现了缩短了服务的时空距 离, 实现了多元服务的时空整合; 在情感维度上，促 进了亲子关系的双向互动, 并且照顾了老人 “独立养 老” 的需求; 在资源维度上, 平衡了对养老资源的单 一依赖压力, 实现了多样资源的整合嵌入。当然, 作 为一种新兴的养老模式, “嵌入式” 家庭养老床位目 前还在发展阶段, 也存在着亟待改进之处。如在顶层 设计上，关于具体服务的指标和收费标准尚未统一; 在资源融合上，如何更好地联动医疗系统实现 “医养 结合” 嵌入也有待完善; 在服务效率上, 服务对象的 认知因素影响设备使用效率, 即出于勤俭观念将部分 联网设施断开，导致无法充分作用等。

综上, 本文结合了实地调查、访谈等方法, 在嵌 入式养老模式的分析基础上，对南京市 $\mathrm{T}$ 社区家庭养老 床位这一具体内容从时空、情感、资源的多维度嵌入 视角探索其运行机制，对该模式的完善具有一定意义。

\section{REFERENCES}

[1] Du Peng, Sun Juan, Zhang Wenjuan, Wang Xuehui. The Demand for the Aged and the Current Situation of Family and Social Resources for the aged in China -Based on the analysis of 2014 China's Elderly Social Tracking Survey [J]. Population research, 2016,40 (06): 49-61

[2] General Report Drafting Group, Li Zhihong. General Report of National Strategy Research on Population Aging [J]. Scientific Research on Aging, 2015,3 (03): 438

[3] Liu Erpeng, Zhang Qilin. Intergenerational Relations, Socio-economic Status and the Elderly's Institutional Pension Willingness: An Empirical Analysis Based on China's Elderly Social Tracking Survey (2012) [J]. Population and Development, 2018,24 (03): 55-64

[4] Regulations of Nanjing Municipality on Elderly Care services [N]. Nanjing Daily. January 21, 2020 (A10)

[5] Liu Shiding. Embeddedness and Relational Contract [J]. Sociological Research, 1999 (4)

[6] HAGEDOORNJ. Understanding the cross-level embeddedness of interfirm partnership formation[J]. Academy of Management Review ,2006,31(3):670-680.

[7] Zukin S, DiMaggio P. The Structures of Capital: The Social Organization of the Economy[M] Cambridge: Cambridge University Press, 1990: 24-69 
[19] LV Xinping. Hospital Care or Community Care? -On the Possible Orientation of China's Elderly Care Model [J]. Population and Economy, 2005 (03): 8-13

[20] Xie Qiong. Bed Vacancy: Need to Review Pension Development Orientation and Policy Support System [N]. China Social News, 2015-08-27 (004)

[21] Mark Granovett. Inlay: Social Network and Economic Action [M]. Translated by Luo Jiade. Beijing: Social Sciences Literature Press, 2007:69

[10] Hu Hongwei, Wang Yu, Wang Xiaojun, Zhang Lan. Status quo, Evaluation and Improvement Path of "Embedded" Pension model [J]. Social Security Research, 2015 (02): 10-17

[11] Zhang Ping. Embedded Pension: Research on Innovation of Elder Care Service Mode in Shanghai [J]. Modern Management Science, 2016 (06): 64-66

[12] Zhao Xiaolan, Meng Yanchun. Community "Embedded" Elder Care Service Mode: Advantages, Difficulties and Solutions [J]. Journal of Hebei University (PHILOSOPHY AND SOCIAL SCIENCES EDITION), 2019,44 (04): 89-95

[13] Wang Jing, Li Pengfei. Advantages and Thinking of Community Embedded Elder Care Service Mode -Based on the Investigation of the Current Situation of Elderly Care service in Developed and Underdeveloped areas [J]. Journal of Social Sciences, Jilin University, 2019,59 (06): 133-139+222

[14] Zhou Yue, Cui Wei. Research on the Development of Beijing's Embedded Elder Care model: a Case Study [J]. New perspective, 2019 (04): 90-96

[15] Nanjing Civil Affairs Bureau. Report on the Information of the Elderly Population and the Development of the Aging Cause [Z]. 2017

[16] Civil Affairs Bureau of Gulou District, Nanjing. Detailed Rules for the management of Family Elder Care Beds in Gulou District (Trial) [Z]. 2018

[17] Jia Yujiao, Fan Jiaxu. From Fracture to Bridging: Changes and Remolding of Family Care Security Function from the Perspective of Time and Space [J]. Social Science Front, 2019 (07): 214-221

[18] Yao Zhaoyu, Chen Risheng, Jiang Haojun. Family Type, Intergenerational Relationship and the Demand for Home-based Elderly Care Service in Rural Areas [J]. Journal of Nanjing University (PHILOSOPHY, Humanities and Social Sciences), 2018,55 (06): 34-42 + $155-156$
[22] Feng Xiaotian. Dependent to Independent " -- An Important Change in the Concept of Elderly Care for the Only Child Family [J]. Hubei Academic Journal. 2006 (03)

[23] Fei Xiaotong. Support for the elderly in the change of family structure -- on the change of family structure in China [J]. Journal of Peking University (PHILOSOPHY AND SOCIAL SCIENCES EDITION), 1983 (03): 7-16

[24] Li Lele. Dependence and Independence: A TwoDimensional Dilemma Analysis of the Choice of Elderly Care mode $[\mathrm{J}]$. Journal of Northwest Agricultural and Forestry University of Science and Technology (SOCIAL SCIENCE EDITION), 2017,17 (06): 147-154 